\title{
Genetic investigation confirmed the clinical phenotype of congenital chloride diarrhea in a Hungarian patient: a case report
}

Éva Dávid ${ }^{1 \dagger}$, Dóra Török ${ }^{2^{* \dagger}}$, Katalin Farkas², Nikoletta Nagy², Emese Horváth², Zsuzsanna Kiss ${ }^{3}$, György Oroszlán ${ }^{1}$, Márta Balogh ${ }^{1}$ and Márta Széll ${ }^{2,4}$

\begin{abstract}
Background: Congenital chloride diarrhea (CCD, OMIM 214700) is a rare autosomal recessively inherited condition characterized by watery diarrhea, hypochloremia and metabolic alkalosis. Mutations of the solute carrier family 26, member 3 (SLC26A3, OMIM 126650) gene are responsible for the disease. The gene encodes a transmembrane protein, which is essential for intestinal chloride absorption.

Case presentation: Here we report a Hungarian boy, presenting the clinical phenotype of CCD. The patient born at 32 weeks of gestation and underwent surgery for abdominal distension and intestinal obstruction related to malrotation. After recovery, electrolyte replacement therapy was necessary due to several periods of diarrhea. After exclusion of other possible causes, increased chloride concentration in the feces supported the diagnosis of CCD. The diagnosis was confirmed by molecular genetic testing. Direct sequencing revealed compound-heterozygosity for a frameshift mutation c.1295delT (p.Leu432Argfs*11) and the known Polish founder mutation c.2024_ 2026dupTCA (p.lle675_Arg676insLeu).

Conclusions: Here we present the clinical symptoms of the first patient in Hungary diagnosed with CCD. Based on the clinical symptoms, stool analysis and genetic testing, the diagnosis of CCD was established. Our study provides expansion for the mutation spectrum of the SLC26A3 gene and the genetic background of CCD.
\end{abstract}

Keywords: Congenital chloride diarrhea, SLC26A3 gene, Compound heterozygous state, Novel mutation, Recurrent mutation

\section{Background}

Congenital chloride diarrhea (CCD, OMIM 214700) is a rare congenital diarrhea of autosomal recessive inheritance. The leading symptoms include intrauterine onset of watery diarrhea, hypokalemia, hypochloremia, hyponatremia and metabolic alkalosis. The disorder was first described in two simultaneous case reports in 1945 [1, 2]. More than 250 cases have been reported since then. The incidence of CCD is variable worldwide. Most cases are sporadic; however, CCD occurs more frequently in Finland, Poland, and in countries around the Persian Gulf, especially in Kuwait and in Saudi Arabia [3, 4].
The gene for CCD, solute carrier family 26 member 3 (SLC26A3, NM_000111) is located on chromosome $7 q 22.3-q 31.1[3,5]$ and encodes a transmembrane protein, which is an apical epithelial $\mathrm{Cl}^{-} / \mathrm{HCO}_{3}{ }^{-}$exchanger expressed on the surface epithelium of the ileum and colon. The malfunction of this anion transporter results in deficient absorption of $\mathrm{Cl}^{-}$and secretion of $\mathrm{HCO}_{3}{ }^{-}$. So far, more than 70 mutations of the gene - including the founder mutations from Finland, Poland and Arabic countries - are known to be pathogenic (http:// www.hgmd.cf.ac.uk). In the present paper, we report the first discovered case of CCD in Hungary and its genetic investigation.

\footnotetext{
* Correspondence: torok.dora@med.u-szeged.hu

†Éva Dávid and Dóra Török contributed equally to this work.

2Department of Medical Genetics, University of Szeged, Szeged, Hungary

Full list of author information is available at the end of the article
}

(c) The Author(s). 2019 Open Access This article is distributed under the terms of the Creative Commons Attribution 4.0 International License (http://creativecommons.org/licenses/by/4.0/) which permits unrestricted use, distribution, and reproduction in any medium, provided you give appropriate credit to the original author(s) and the source, provide a link to the Creative Commons license, and indicate if changes were made. The Creative Commons Public Domain Dedication waiver (http://creativecommons.org/publicdomain/zero/1.0/) applies to the data made available in this article, unless otherwise stated. 


\section{Case presentation}

The premature boy, born by Cesarean section at 32 weeks of gestation, had a birthweight of $1850 \mathrm{~g}$ and Apgar scores of 6/1 and 9/5. Prenatal ultrasound was performed at 24 weeks of gestation and showed small bowel dilatation of the fetus and increased flow in the ascending aorta. The newborn had abdominal distension and had thin, fluid-like discharge from the rectum. Abdominal radiographs showed small bowel ileus (Fig. 1). On postnatal day 2, laparotomy was performed revealing a type 1 malrotation of the gut associated with obstructing Ladd's Bands. On postnatal day 12, the newborn developed symptoms of late-onset sepsis caused by Klebsiella pneumoniae. Gastrointestinal bleeding, pulmonary hemorrhage and a small intracranial hemorrhage were also present. The patient had bilious emesis and failure to pass stool. Imaging studies showed dilated loops of the bowel; therefore, detorquation of a bowel loop and adhesiolysis were performed. After reoperation, he tolerated feeding and gained weight; however, repeated blood analyses indicated hyponatremia, hypochloremia, hypokalemia and metabolic alkalosis, necessitating prolonged oral electrolyte replacement therapy. Sweat test showed normal chloride concentrations and direct sequencing of the coding regions of the cystic fibrosis transmembrane conductance regulator (CFTR) gene revealed a single

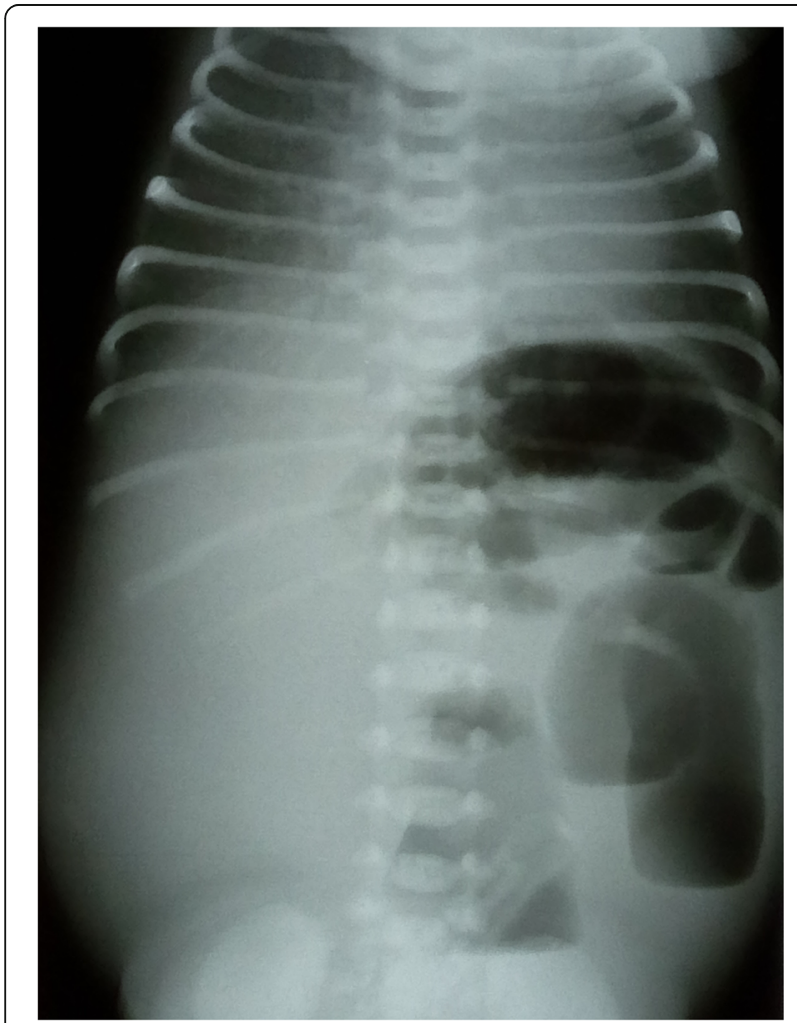

Fig. 1 Simple abdominal radiography. Imaging study on the first life day shows small bowel ileus delta F508 mutation. The infant had frequent loose stools, sometimes 6-10 times per day. In the first year of life, he was frequently admitted to the hospital because of viral infections and dehydration, and needed electrolyte replacement in increasing amounts. A 24-h urine collection test showed low concentrations of sodium, potassium and chloride ions (9.7 $\mathrm{mmol} / \mathrm{l}, \quad 14.9 \mathrm{mmol} / \mathrm{l}$ and $6.6 \mathrm{mmol} / \mathrm{l}$, respectively). Plasma renin activity $(34.2 \mathrm{mg} / \mathrm{ml} / \mathrm{h})$ and aldosterone $(51 \mathrm{mg} / \mathrm{dl})$ levels were increased, suggesting secondary hyperaldosteronism. After exclusion of other possible causes, chloride loss in the feces was detected. Elevated chloride concentrations were detected in centrifuged feces samples (148 and $154 \mathrm{mmol} / \mathrm{l}$; normal range is below $90 \mathrm{mmol} / \mathrm{l}$ ) using standard chemistry analysis. Based on the high chloride levels in the stool, diagnosis of CCD was established.

To perform molecular genetic confirmation, peripheral blood samples were drawn from the affected patient and from his unaffected family members $(n=2)$, as well as from unrelated healthy controls $(n=50)$, and genomic DNA was isolated from the blood samples. The coding regions and the flanking introns of the $S L C 26 A 3$ gene were amplified and sequenced. Direct sequencing of the investigated regions of the SLC26A3 gene revealed two heterozygous mutations: a novel thymine-base deletion (c.1295delT, p.Leu432Argfs*11, Fig. 2a) in exon 11 and a recurrent 3-base (TCA) duplication (c.2024_2026dupTCA, p.Ile675 _Arg676insIle, Fig. 2b) in exon 18. After the disease-causing mutations were identified in the patient, the mutation status of the parents was determined (Fig. 3). The clinically unaffected parents carry the mutations in heterozygous form, and all unrelated healthy controls $(n=50)$ carry the wild type sequence.

After establishing the diagnosis, oral electrolyte supplementation was continued with $2,1 \mathrm{~g}$ of $\mathrm{NaCl}$ and $2,2 \mathrm{~g}$ of $\mathrm{KCl}$ a day, and proton pump-inhibitor therapy was also administered to inhibit gastric $\mathrm{Cl}^{-}$secretion. [6, 7] Since then no parenteral fluid replacement therapy was necessary, as electrolytes were in normal range and alkalosis did not recurred. 12 months after the conclusion of the genetic analysis, the patient has stools still 6-8 times a day, but successfully underwent toilet training. Currently at the age of 4 , his weight is at 25 percentile $(16 \mathrm{~kg})$, his psychomotor development is appropriate for age, he attends nursery school.

\section{Discussion and conclusions}

CCD is a rare autosomal recessive disorder caused by homozygous and compound heterozygous mutations of the $S L C 26 A 3$ gene. The clinical diagnosis is mainly based on the clinical history, characteristic metabolic abnormalities and high levels of chloride in stool. The symptoms and signs frequently overlap with other 


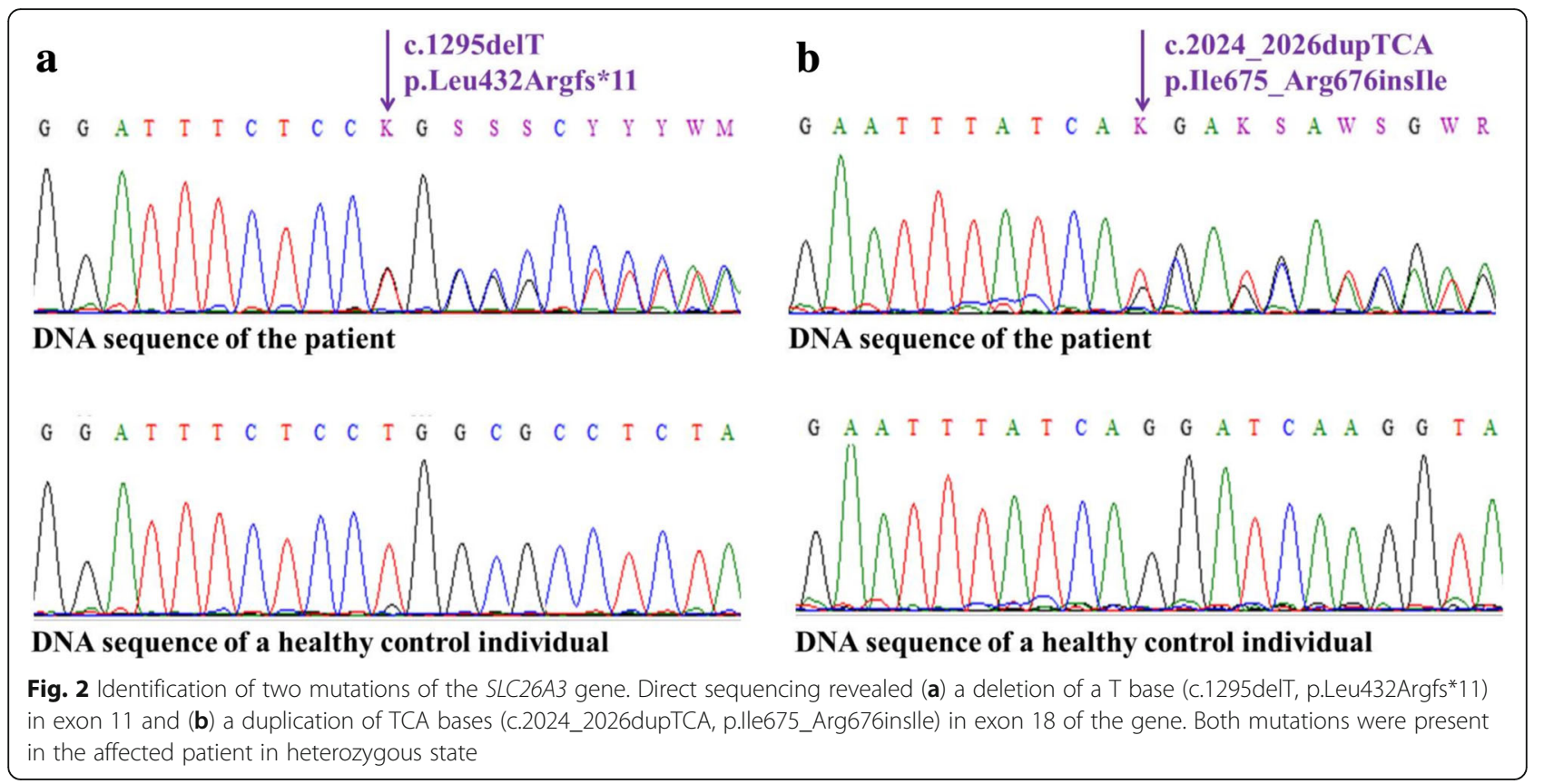

conditions, such as cystic fibrosis and Bartter syndrome. Clinical history as well as urinary and sweat chloride levels help in the differentiation of these diseases (Table 1) [8-10].

Due to absence of known hotspots in the SLC26A3 gene in the Hungarian population, molecular genetic confirmation of the CCD clinical diagnosis is usually performed by sequencing the entire coding region of the gene. Most of the known mutations are point mutations or small deletions, many of which affect exon 3-6 and 12-15 [10].

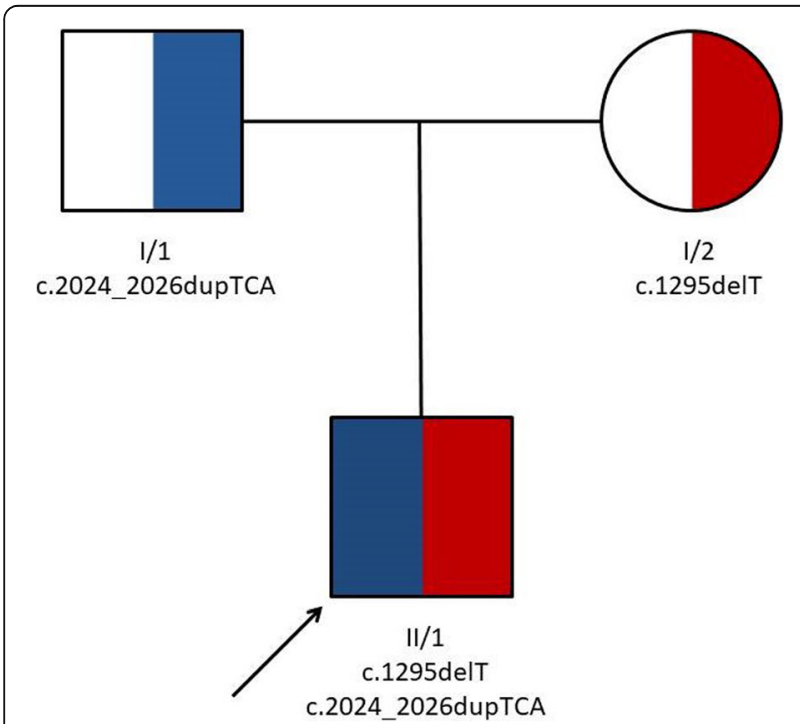

Fig. 3 Pedigree of the investigated Hungarian patient. The patient (II/1) was the only clinically affected individual in his pedigree: his parents (I/1 and I/2) were clinically unaffected
In populations in which founder effects have been observed (Finland, Poland, Saudi Arabia and Kuwait), single-mutation analysis of the typical founder mutation is the first test performed [4].

The present case is the first Hungarian patient diagnosed with CCD. The condition in the index patient was caused by compound heterozygous mutations in the SLC26A3 gene. A novel thymine-base deletion (c.1295delT, p.Leu432Argfs*11) was identified in exon 11 (Fig. 3a) leading to the development of a premature termination codon. This newly identified mutation has not been reported in any SNP database (ExAC, 1000 Genome Project, ESP). The pathogenicity of this novel variation was suggested by the clinical context and the fact that the mutation truncates the 3 ' half of the predicted protein. A recurrent 3-base (TCA) duplication (c.2024_2026dupTCA, p.Ile675_Arg676insIle) was detected in exon 18 (Fig. 3b), resulting in the incorporation of an additional amino acid into the protein. This recurrent disease-causing mutation is a founder mutation in the Polish population and is involved in almost $50 \%$ of the CCD-associated cases in Poland [4]. Parents of the reported patient are not aware of any Polish relatives.

Undiagnosed CCD is a severe condition. Only rare cases are known to have survived after the first year undiagnosed. In an affected child, an acute gastroenteritis can lead to life-threatening dehydration and hypokalemia. Lifelong electrolyte supplementation to correct the biochemical abnormalities with $\mathrm{NaCl}$ and $\mathrm{KCl}$ is the basis of management. Timely and adequate therapy determines the outcome, normal growth and development of the affected child and requires early 
Table 1 Comparison of the clinical phenotype of differential diagnostic disorders

\begin{tabular}{|c|c|c|c|}
\hline Disorder & CCD & Bartter syndrome & Cystic fibrosis \\
\hline \multicolumn{4}{|l|}{ Characteristic } \\
\hline Onset of disease & Presents early in neonates & Presents in infants, but can present later & $\begin{array}{l}\text { Presents primarily in neonates } \\
\text { and infants }\end{array}$ \\
\hline $\mathrm{Cl}^{-}$concentration in urine & Low & High & Low \\
\hline $\mathrm{Cl}^{-}$concentration in stool & Elevated in watery stool & Not detected in normal stool & Not detected in fatty or normal stool \\
\hline Sweat $\mathrm{Cl}^{-}$test results & Can be elevated & Normal & High \\
\hline Blood pH & Metabolic alkalosis & Metabolic alkalosis & Metabolic alkalosis \\
\hline Possible electrolyte disturbances & $\begin{array}{l}\text { Hyponatremia, hypochloremia } \\
\text { and hypokalemia }\end{array}$ & $\begin{array}{l}\text { Hyponatremia, hypochloremia } \\
\text { and hypokalemia }\end{array}$ & $\begin{array}{l}\text { Hyponatremia, hypochloremia } \\
\text { and hypokalemia }\end{array}$ \\
\hline
\end{tabular}

and sufficient supplementation. Patients require fastidious follow-up to prevent long-term complications, such as renal failure and hyperuricemia [11]. A correct diagnosis of $\mathrm{CCD}$ has an important impact on family planning and allows preimplantation genetic diagnosis and prenatal diagnostics.

\section{Abbreviations}

CCD: Congenital chloride diarrhea; CFTR: Cystic fibrosis transmembrane conductance regulator; SLC26A3: Solute carrier family 26 member 3

\section{Acknowledgements}

We would like to thank all the patients and healthy control individuals for participating in this investigation. We would like to thank Ferenc Hadarits MD PhD and the staff of Central Laboratory, Markusovszky Teaching Hospital for performing the investigation of feces samples and helping in establishing the diagnosis.

\section{Funding}

This study was supported by the GINOP-2.3.2-15-2016-00039 and EFOP-3.6.116-2016-00008.

\section{Availability of data and materials}

All data generated or analysed during this study are included in this published article.

\section{Authors' contributions}

É.D. cared for patient and contributed to writing the initial manuscript. D.T. performed the genetic analysis and contributed to writing the initial manuscript. K.F. performed the genetic analysis and participated in manuscript preparation. N.N., E.H. and Zs.K. participated in the genetic analysis. Gy.O., M.B. and M.Sz. were mentors who guided the research study. All authors read and approved the final manuscript.

\section{Ethics approval and consent to participate}

The investigation was approved by the Internal Review Board of the University of Szeged. Written informed consent was obtained from the patients and unrelated healthy individuals. The study was conducted according to the Principles of the Declaration of Helsinki.

\section{Consent for publication}

Written informed consent for publication of their clinical details and clinical images was obtained from the father of the patient and the parents. A copy of the consent form is available for review by the Editor of this journal.

\section{Competing interests}

The authors declare that they have no competing interests.

\section{Publisher's Note}

Springer Nature remains neutral with regard to jurisdictional claims in published maps and institutional affiliations.

\section{Author details}

${ }^{1}$ Department of Pediatrics, Markusovszky Teaching Hospital, Szombathely, Hungary. ${ }^{2}$ Department of Medical Genetics, University of Szeged, Szeged, Hungary. ${ }^{3}$ Genetic Counseling Outpatient Clinic, Markusovszky Teaching Hospital, Szombathely, Hungary. ${ }^{4}$ MTA-SZTE Dermatological Research Group, University of Szeged, Szeged, Hungary.

Received: 2 October 2018 Accepted: 2 January 2019

Published online: 11 January 2019

\section{References}

1. Gamble JL, Fahey KR, Appleton J, MacLachlan E. Congenital alkalosis with diarrhea. J Pediatr. 1945;26:509-18.

2. Darrow DC. Congenital alkalosis with diarrhea. J Pediatr. 1945;26:519-32.

3. Mäkelä S, Kere J, Holmberg C, Höglund P. SLC26A3 mutations in congenital chloride diarrhea. Hum Mutat. 2002;20:425-38.

4. Amato F, Cardillo G, Liguori R, Scorza M, Comegna M, Elce A, et al. Twelve novel mutations in the SLC26A3 gene in 17 sporadic cases of congenital chloride diarrhea. J Pediatr Gastroenterol Nutr. 2017;65:26-30.

5. Wedenoja S, Pekansaari E, Höglund P, Mäkelä S, Holmberg C, Kere J. Update on SLC26A3 mutations in congenital chloride diarrhea. Hum Mutat. 2011;32: 715-22.

6. Wedenoja S, Höglund P, Holmberg C. Review article: the clinical management of congenital chloride diarrhoea. Aliment Pharmacol Ther. 2010;31:477-85.

7. Aichbichler BW, Zerr CH, Santa Ana CA, Porter JL, Fordtran JS. Proton-pump inhibition of gastric chloride secretion in congenital chloridorrhea. N Engl J Med. 1997;336:106-9.

8. Shamaly $H$, Jamalia J, Omari $H$, Shalev S, Elias N. Congenital chloride diarrhea presenting in newborn as a rare cause of meconium ileus. J Perinatol. 2013;33:154-6.

9. Saneian H, Bahraminia E. Congenital chloride diarrhea misdiagnosed as pseudo-Bartter syndrome. J Res Med Sci. 2013;18:822-4.

10. Bhardwaj S, Pandit D, Sinha A, Hari P, Cheong HI, Bagga A. Congenital chloride diarrhea - novel mutation in SLC26A3 gene. Indian J Pediatr. 2016; 83:859-61.

11. Hihnala S, Höglund P, Lammi L, Kokkonen J, Ormälä T, Holmberg C. Longterm clinical outcome in patients with congenital chloride diarrhea. J Pediatr Gastroenterol Nutr. 2006:42:369-75.

Ready to submit your research? Choose BMC and benefit from:

- fast, convenient online submission

- thorough peer review by experienced researchers in your field

- rapid publication on acceptance

- support for research data, including large and complex data types

- gold Open Access which fosters wider collaboration and increased citations

- maximum visibility for your research: over $100 \mathrm{M}$ website views per year

At BMC, research is always in progress.

Learn more biomedcentral.com/submissions 